\title{
Cartas entre el arquitecto Héctor Greslebin y estudiosos peruanos en torno al Cuzco. Una antología (1932-1943)
}

Isabel Iriarte

Este artículo se propone, a través de la publicación de un grupo de cartas, el dar a conocer algunos de los ejes alrededor de los cuales giró a lo largo de más de veinte años, la vinculación del arquitecto Héctor Greslebin con una serie de intelectuales peruanos ligados con el quehacer arqueológico en ese país. La correspondencia seleccionada en esta ocasión se articula en torno a la necesidad de promover los estudios del pasado arqueológico del Cuzco, a través del apoyo al Instituto Arqueológico de Cuzco, de su posible internacionalización y de la creación de la Sección Arqueología en la Universidad de Cuzco. Las cartas van desde agosto de 1932 hasta diciembre de 1943 y la mayor parte de ellas se intercambian entre Greslebin y Valcárcel1.

\section{Héctor Greslebin, arquitecto y arqueólogo}

\section{El arquitecto Héctor Greslebin}

${ }^{1}$ En un próximo art́culo se dará a conocer la correspondencia que Greslebin mantuvo con Julio Tello, Rafael Larco Herrera, Rafael Larco Hoyle, Fortunato Herrera, Urteaga, etc.
(Buenos Aires 1893-1971) es una figura de referencia en la Argentina, tanto para la historia de la arquitectura como para la historia de la arqueología.

Aunque su producción como arquitecto no fue extensa, es sin embargo la que le ha valido más trascendencia, por representar una propuesta de incorporar al lenguaje arquitectónico elementos de las antiguas culturas americanas, que ayudaran a configurar, en el plano artístico, una identidad nacional2. Esta búsqueda que en la Argentina va a tener en Ricardo Rojas a una figura clave, debía extenderse, tanto para Rojas como para Greslebin, a todos los campos del diseño aplicado. De modo tal que Greslebin no sólo producirá proyectos arquitectónicos algunos de los cuales se construirán, mientras otros sólo quedarán en los planos - sino que

${ }^{2}$ Vease Schávelzon, Daniel y Beatriz Patu, "La búsqueda de un arte y una arquitectura americana: Héctor Greslebin 1893-1971", en Cuadernos de Historia del arte $\mathbf{N}^{\circ} \mathbf{1 4}$, pp. 37-63. Mendoza, Instituto de Historia del Arte, Facultad de Filosoffa y Letras de la Universidad Nacional de Cuyo, 1992; y Patti, Beatriz y Daniel Schávelzon, "Los intentos por la creación de una Estética Nacional", en Boletín de Arte, Instituto de Historia del Arte Argentino y Americano, Facultad de Bellas Artes, Universidad Nacional de Lal Plata, Año $15 \mathrm{n}^{\circ} 10$, sepliembre 1993, pp. 12-23. 
llegará a hacer propuestas para diseños de alfombras basados en motivos arqueológicos del noroeste argentino.

Greslebin realiza además un importante aporte como estudioso de algunos aspectos de la arquitectura colonial y hasta el día de hoy es de consulta indispensable su trabajo sobre los túneles coloniales de la ciudad de Buenos Aires. También será docente de Historia de la Arquitectura en la Universidad, donde introducirá por primera vez el estudio de la arquitectura precolombina.

En cuanto a la arqueología, es sobre todo la fascinación por la dimensión artística de los objetos producidos por las antiguas culturas precolombinas, lo que lo va a acercar a esta disciplina.

Recién recibido de arquitecto, concurre al Museo de Ciencias Naturales Bernardino Rivadavia para dibujar motivos de cerámica del noroeste argentino. En estas circunstancias conoce a Eric Boman, jefe de la Sección Arqueología de dicho museo, quien rápidamente, al advertir su capacidad para el dibujo y su interés por la arqueología, le propone trabajar con él3. A la muerte de Bohman, en 1924, le ofrecen su puesto en el Museo, y la primera tarea que le encomiendan, a los pocos días de ser nombrado, es la de representar al Museo en la delegación argentina que asistirá al Tercer Congreso Científico Panamericano que se iba a reunir en Lima a fines de diciembre de ese mismo año.

Al regreso de su viaje, y hasta 1930 en que renuncia a su puesto, Greslebin estará a cargo de las colecciones arqueológicas del Museo y se ocupará con especial esmero de las colecciones peruanas que él mismo ayudó a incrementar con los objetos traídos de su viaje. Su labor no se limitará al acondicionamiento y catalogación de las piezas sino que va a valerse de publicaciones, conferencias y hasta de programas de radio para difundir el arte peruano, además de incorporarlo a los programas de los

\footnotetext{
${ }^{3}$ Boman, Eric y Héctor Greslebin Alfarería de estilo draconiano de la
} Región Diaguita,Imp. Ferrari Hnos, Buenos Aires, 1923. cursos que dicta en el Instituto Nacional del Profesorado donde será profesor de Prehistoria, Arqueología y Protohistoria argentina y americana hasta su jubilación en 1960.

Sin embargo, a pesar de su entusiasmo por la arqueología, y en especial por el Perú, el mismo Greslebin reconoció que su situación se volvió crítica luego de su renuncia al Museo. En el prólogo a su Curriculum, redactado en los últimos años de su vida, dice Greslebin: "Mi franca dedicación al estudio de la arqueología americana desde los primeros años de mi juventud, estimulada por el ejemplo vivido por mi padre y convalidada por la adquisición temprana de importantes cargos oficiales, prometía según sincero juicio actual, de mi parte un rendimiento específico mayor sobre esta ciencia, que el que se señala en este Curriculum. (...) También este Curriculum, amplio, porque no es ninguna presentación a concurso, quiere justificar con sus números, el porqué luego de haber alcanzado en temprana edad una relevante ubicación científica oficial, al verme privado de su apoyo, al no poder disponer de sus páginas, me vi obligado a dedicarme a la enseñanza, pues me hallaba apartado de mi profesión. Por desgracia, me tocó enseñar materias muy diferentes entre sí, con lo que se pierde profundidad en el conocimiento. Mas, en cambio, tuve la ocasión de aplicar sus principios a la arqueología y por ello $\mathrm{mi}$ tendencia a desarrollar sobre sus temas mis conocimientos artísticos y arquitectónicos."

Aunque Greslebin seguirá publicando trabajos sobre temas de arqueología, se va a sentir progresivamente marginado del ambiente académico. En una carta del 5 de octubre de 1932 se queja a Valcárcel: "Parece que "se han olvidado" de ponerme en la comisión Ejecutiva del próximo Congreso Internacional de Americanistas [a celebrarse en la ciudad de La Plata]. Indudablemente, mi retiro voluntario del Museo de $\mathrm{H}$. Natural ha tenido la virtud de hacer descender mis acciones entre el elemento oficial."

En 1935 renuncia a su cargo de Adscripto Honorario al Museo Etnográfico "Juan 
B. Ambrosetti", debido a que dicho museo rechaza su pedido de llevar su representación a Lima en ocasión de haber sido invitado oficialmente a los actos por el IV Centenario de la fundación de la ciudad.

\section{La correspondencia y otras modalidades de contacto con el Perú}

Sin embargo, esta situación desventajosa dentro del propio país, no va a afectar el desarrollo de sus vinculaciones con el Perú. Se podría decir que ellas son en gran medida el resultado de una decisión y una iniciativa puramente personales. Él mismo parece consciente de ello cuando le dice a Valcárcel, en la carta citada más arriba: "Creo que soy el único que se ocupa de mantener el contacto con los demás colegas de América". Y lo hace sin otro respaldo que la impresión favorable que había causado en sus interlocutores en su primera visita al Perú, y que va a mantener viva con sus cartas y el envío de sus publicaciones. De hecho su relación con Valcárcel, luego de un primer encuentro en Lima en 1924, se reiniciará por carta en 1932 cuando Greslebin ya se considera a sí mismo fuera del sistema.

A lo largo de los años y en varias de sus cartas, Greslebin manifiesta su intención de volver al Perú pero su situación económica no se lo permitirá y sólo llegará a realizar un segundo viaje en 1935, invitado por la Municipalidad de Lima a los actos por la celebración del Cuarto Centenario de la fundación de la ciudad.

A pesar de no poder viajar, no va a descuidar su conexión con ese país. Su nombre va a estar asociado con la difusión de distintos aspectos de la cultura peruana 4 , y mantendrá además, un trato fluido con representantes de la

\footnotetext{
${ }^{4}$ En las dos décadas siguientes a su primer viaje al Penú, Greslebin encarará la difusión del Perú y de su pasado, por varias vaas: publicará articulos en distintos diarios de la Argentina, dictiurá un número considerable de conferencias en ámbitos diversos. producirá artículos para publicaciones cientficas, dará cursos, y hasta realizará programas radiales. Un listado de la bibliograffa producida por Greslebin se encuentra en J. Cáceres Freyre, "Héctor Greslebin (1893-1971)", en Cuadernos del Instituto Nacional de Antropología, no8,1972-1978, pp. 212-219, Buenos Aires.
}

colectividad peruana y con diplomáticos del Perú en la Argentina. Estos últimos contactos serán en definitiva los que le permitan propiciar desde Buenos Aires una resolución favorable de la situación del Instituto Arqueológico de Cuzco.

\section{Los viajes al Perú de 1924 y de 1935}

En diciembre de 1924, viajará al Perú como delegado del Gobierno Argentino, de la Facultad de Ciencias Exactas Físicas y Naturales, del Instituto Nacional del Profesorado Secundario, y del Museo Nacional de Historia Natural "Bernardino Rivadavia" de Buenos Aires, al Tercer Congreso Científico Panamericano de Lima. Asistirá a la subsección de Arqueología y Prehistoria de dicho congreso, donde presentará dos trabajos: el que había realizado con Boman, "Alfarería de estilo draconiano de la región diaguita", y "Fisiografía y Noticia preliminar sobre arqueología de la región de Sayape". En la subsección de Arquitectura y Construcción presenta "Aplicación de los temas decorativos de origen americano a la arquitectura".

Como complemento a las reuniones de la subsección de Arqueología, los delegados realizarán excursiones a Armatambo, Chillón y Pachacamac. En Chillón, acompañado por Tello, extraerá dos momias con sus ajuares, una de adulto y otra de niño, las cuales Tello le autorizará a llevar para el Museo de Buenos Aires ${ }^{5}$.

Finalizado el Congreso es invitado junto con otros delegados, por el Gobierno del Perú, a visitar la ciudad de Cuzco donde permanece unos días y recorre las ruinas incas. En su regreso a Buenos Aires pasará por La Paz.

Su segundo viaje al Perú lo realizará en 1935 como invitado de la Municipalidad de Lima a los actos de conmemoración del cuarto centenario de la fundación. de la ciudad. En carta a Valcárcel del 13 de noviembre del 34 dice al

\footnotetext{
${ }^{5}$ El informe sobre estas momias lo publicará en las Actas del XXII Congreso Internacional de Americanistas de Roma, en. 1928.
} 
respecto: "El señor Embajador del Perú, Dr. Felipe Barreda y Laos, ha hecho gestiones para que el Perú me considere invitado oficial a las próximas fiestas del Centenario de Lima y me ha comunicado que ha sido resuelto el punto favorablemente (...)"

En carta del 30 de junio del 35, a Mario Fontana Company de Montevideo, resume su viaje: "(...)Acabo de hacer un espléndido viaje a Chile y al Perú, en los meses de enero y febrero, viaje que me fue costeado por el gobierno del Perú para que diera conferencias en Lima, en ocasión de las fiestas tetracentenarias de su fundación. He recibido una verdadera sorpresa por los homenajes de que me han hecho objeto. Me nombraron miembro correspondiente del Instituto Histórico del Perú, y me obsequiaron con una placa de oro los intelectuales y artistas del Cusco, en acto público. En mis conferencias me fue muy bien y los diarios llenaron páginas enteras con mi nombre. Todo esto contrasta con las miserias de aqui y contribuye a reconfortar nuestro ánimo."

Anteriormente, el 12 de marzo de ese mismo año le escribía a Gualterio Looser de Santiago de Chile: (...) "Realicé también un viaje completo en avión por la región Chimú y exploré durante seis dias por las ruinas y huacas de la costa. He quedado muy impresionado de la obra seria que está realizando Rafael Larco Hoyle.(...)"6

Entre las actividades que desarrolla en Lima, se pueden mencionar la conferencia en la Sociedad Geográfica de Lima, sobre "El estilo arcaico de América", los discursos en el Rotary Club de Lima, en el Instituto Histórico del Perú con motivo de su incorporación al mismo, y el que pronuncia en la entrega de la placa a la Municipalidad de Lima por parte de la Delegación Argentina al IV Centenario. De todos estos acontecimientos van a ir dando cuenta los diarios de Lima?.

\footnotetext{
${ }^{6}$ En ese recorrido será acompañado por Rafael Larco Hoyle tal como lo atestigua el artículo con fotografías tomadas por el mismo Greslebin, publicado en La Prensa, 8 de septiembre de 1935, , sección cuarta, Buenos Aires.

${ }^{7}$ Vease La Prensa, 27, 29 y 31 de enero de 1935; La Crónica, 31 de enero y I y 2 de febrero de 1935; El Comercio, 31 de enero y 1 de febrero de 1935.
}

Además, en El Comercio se le publicarán dos artículos y se le hará un reportaje ${ }^{8}$. La Crónica, por su parte, le publicará un artículo y dará además una semblanza de su figura, bajo el título "Figuras de nuestra América. Héctor Greslebin" Allí, el autor de la nota, Carlos Ríos Pagaza, señala: "Y es para honor nuestro y provecho de la ciencia peruana el que Greslebin haya empleado muchas horas de sus fecundas vigilias en ahondar los problemas del Perú precolombino y dilucidarlos bella y diáfanamente como si acaecieran hoy, como si los tuviera a la vista.(...) En el $25^{\circ}$ Congreso de Americanistas de La Plata Héctor Greslebin, en unión de ese otro peruanista insigne que es Martín Noel, propugnó la ponencia de declarar el CUZCO, CAPITAL ARQUEOLOGICA DE LA AMERICA DEL SUR, venciendo la tenaz resistencia que opuso Posnansky, quien quería ese honor para TIAWANAKO.

Cuzco y el Perú todo, deben a ese arqueólogo eminente, pues el justiciero homenaje que significa la sobredicha designación, y en buena parte, la creación del Instituto Internacional de Arqueología, con sede en la Ciudad Imperial (...)"9.

\section{La vigencia de la figura de Héctor Greslebin en el Perú}

El reconocimiento del que va a gozar Greslebin en el Perú, a partir de su primer viaje, se mantendrá a lo largo de los años. No van a ser sólo las cartas que intercambia con personalidades peruanas las que reflejen esta situación. La serie de nombramientos $e$ invitaciones a publicar en el Perú, y a asistir a reuniones científicas, que se enumeran a continuación, sugieren que siguió siendo considerado como una figura relevante por mucho tiempo.

\footnotetext{
8"Impresiones al regresar a Lima en 1935, después de diez años", El Comercio, 18 de enero de 1935,p. 24; "Consideraciones sobre el viaje al Perú", El Comercio, 16 de febrero de 1935; "Conversando con el intelectual argentino, señor Héctor Greslebin", El Comercio, $1^{\circ}$ de febrero de 1935.

9 "Conociendo la arqueología del Norte del Perú se aclarará el problema de la cronología de las culturas peruanas", en La Crónica, 9 de febrero de 1935 Lima. "Figuras de nuestra América. Héctor Greslebin", en La Crónica, 14 de febrero de 1935, Lima.
} 
- Socio honorario de la Sociedad Geográfica de Lima, 5 de enero de 1925-Delegado al XXV Congreso Internacional de Americanistas de la Plata, 1932, del Museo Nacional de Lima. (Véase correspondencia con Valcárcel, más abajo)

- Publica "La tendencia a la "simetría dinámica" en la forma aríbalo de la cerámica del Cuzco", en Revista del Museo Nacional, t. III, no 1 y 2, pp. 164-167,Lima, 1934.

- Miembro correspondiente del Instituto Histórico del Perú. 18 de enero de $1935^{10}$.

- Invitado a la Conferencia Arqueológica de Trujillo, mayo de 1936. (Véase correspondencia con Valcárcel, más abajo) ${ }^{11}$.

- Socio corresponsal del "Seminario de Altos Estudios del Instituto Arqueológico del Cuzco", 14 de enero de 1936. (Véase correspondencia con Pardo, más abajo).

- Invitado a fundar la Sección de Arqueología de la Universidad Nacional de Cuzco, noviembre de 1943. (Véase correspondencia con Pardo, más abajo).

- Socio correspondiente del Centro de Cultura de Ica, Perú. 10 de agosto de $1942^{12}$.

- Publica "Cuzco capital arqueológica de Sud América", en Revista del Instituto y Museo Arqueológico de la Universidad del Cuzco. Edición conmemorativa del primer centenario de la fundación del Museo, № 12, pp. 139-142,

\footnotetext{
${ }^{10}$ En carta del 21 de enero de 1935, Horacio Urteaga le comunica que el Directorio del Instituto "...ha tenido a bien, considerando su dedicación sobresaliente a los estudios de Historia Americana, incorporarlo a la institución en calidad de CORRESPONDIENTE..."

I'También Larco Herrera lo invita, en su calidad de Vicepresidente del Congreso de Trujillo. En carta del 15 de febrero de 1935, le escribe: "Estimo que su presencia en el citado Congreso Arqueológico, sería el más valioso contingente que podría aportarse para el estudio y esclarecimiento de interesantes asuntos relacionados con las civilizaciones Muchik y Chimú."

12"Tengo la viva complacencia de poner en conocimiento de Ud. que el Consejo Directivo del Centro de Cultura que me honro en presidir, ha acordado designarlo su socio correspondiente en esa ciudad, en virtud de sus merecimientos intelectuales, de su entusiasmo por la cultura americana, y a propuesta mfa y de D. Próspero L. Belli, Tesorero de esta institución." Carta de Alberto Casa Vilca, presidente del Centro de Cultura Ica, Ica, 10 de agosto de 1942 .
}

julio de 1948, Cuzco.

- Invitado especial de la Universidad Mayor de San Marcos de Lima al Primer Congreso Internacional de Peruanistas. 15 de junio de 1951, Lima , Perú13.

\section{Correspondencia}

En esta ocasión se ha seleccionado la correspondencia de Greslebin con Luis E. Valcárcel, Luis Pardo, Dr. Carlos Bambarén, Gualterio Looser, y el Ministro de Relaciones Exteriores del Perú, Dr. Carlos Concha. Da la impresión de que faltan algunas cartas. De hecho Greslebin hace referencia a una carta de Valcárcel que no se conserva. Además, llama la atención que no le escriba a Valcárcel para comentarle el ofrecimiento que le hace Luis Pardo en 1943. La corrrespondencia conservada con Valcárcel llega hasta 1938.

En la reproducción de las cartas se ha mantenido un orden cronológico con independencia de los destinatarios.

\section{8.1932 (De Greslebin a Valcárcel)}

Estimado y muy distinguido colega:

Varias veces he intentado comunicarme con usted por correspondencia dirigiéndome a su dirección de Cuzco. Ultimamente escribí al profesor Fortunato Herrera de Cuzco pidiéndole la dirección suya, la del Dr. Gabriel Cossio y del Dr. José Baca, pero no he tenido contestación alguna. Una nueva publicación del Museo de su digna dirección en ésa, que acabo de ojear en una

\footnotetext{
${ }^{13}$ En la carta de invitación del 15 de junio de 1951, firmada por Raúl Porras Barrenechea y Ella Dunbar Temple, presidente y secretaria de la Comisión Organizadora, se le comunica a Greslebin:"Es para esta Comisión motivo de particular complacencia asumir el honroso cometido de poner en su conocimiento que, por votación unánime, se acordó designar a Ud. como invitado especial de la Universidad al Primer Congreso Internacional de Peruanistas. La Comisión ha cnmplido así un justiciero acto de reconocimiento a sus claros méritos en la labor historica y a su acendrada y significativa obra de valoración y esclarecimiento de la cultura peruana." En la misma carta se le pide que envíe una ponencia. Aunque Greslebin no asistió, sí mandó un trabajo: "La técnica antisísmica en la arquitectura de los Incas."
} 
librería me dice que está usted en Lima y me apresuro a darle mis noticias de continuar estos estudios a pesar de haberme retirado voluntariamente del Museo Nacional de Historia Natural de esta. Por el mismo correo le envio en concepto de canje la serie de trabajos míos sobre arqueología que usted aún no ha recibido por el motivo anterior de carecer de su dirección.

Celebro sinceramennte la nueva importante misión que se le ha confiado y le felicito. Espero que este año tendré el placer de verle en esta con motivo de la celebración del Congreso Internacional de Americanistas que se celebrará en La Plata el 19 de noviembre próximo, según acaban de resolverlo sus autoridades ejecutivas, contrariamente a lo que se había anunciado de dejarlo para el próximo año. Yo sigo prestando servicios honorariamente en el Museo Etnográfico y continúo como profesor titular de arqueología americana en el Instituto Nacional de Profesorado Secundario. Por todo ello es que ruego a usted me ponga al corriente de sus nuevos trabajos y de la Revista que edita el Museo, si ello fuera posible.

Lo saluda con su consideración más distinguida, esperando sus noticias.

Héctor Greslebin

\subsubsection{2 (De Valcárcel a Greslebin)}

Muy recordado colega:

Un gran gusto he tenido al recibir su amable carta y los interesantísimos folletos arqueológicos de que es Ud autor. Mil gracias.

Estuve deseoso de escribirle, pero carecía de su dirección. En ocho años que no nos vemos han pasado demasiadas cosas. Aquí me tiene, al frente de este Museo, desde octubre de 1930. Vine a reemplazar al amigo Tello, quien dentro de la nueva situación política,desgraciadamente sufrió rudos ataques porque nuestro colega fue diputado durante el régimen Leguía y muy adicto de éste. El Museo está reorganizado, como verá Ud. por el Estatuto que le envío. Admirador y amigo de Tello, éste no se ha alejado de su centro de actividades arqueológicas por mi decidida voluntad de apoyarlo en sus estudios. He creado una sección especial para él -el Instituto de Investigaciones Antropológicas-, donde trabaja con toda independencia, entregado a la investigación. Creo, compañero, que he cumplido con mi deber.

El amigo Dr. José Grabriel Cossio es actualmente director del Colegio Nacional de Trujillo. Jenaro Fernández Baca, y no José, continúa en el Cusco y puede Ud. escribirle con esa dirección. El Dr. Fortunato Herrera es rector de la Universidad del Cusco. El Dr. Luis A. Pardo me reemplaza en dicho centro.(...) Por este correo le mando el primer número de la revista, cuyo segundo está en prensa. Le he inscrito.

El Museo agradecerá a Ud. el envío de sus trabajos y la revista tendrá placer en publicar algo suyo inédito.

Con afectuosos recuerdos, soy su compañero y amigo muy adicto.

Luis E. Valcárcel

\subsubsection{2 (De Greslebin a Valcárcel)}

Muy apreciado amigo y distinguido colega:

Tengo el agrado de acusar recibo de su muy atenta del 31 de agosto pasado y también de la Revista del Museo Nacional de Lima. Le agradezco nuevamente el envío de esta interesante publicación y le felicito por su programa de acción, deseándole sinceramente que no carezca de la ayuda necesaria para llevar a cabo sus propósitos, pues es de descontar su positivo y sincero entusiasmo para cumplirlo. Voy a escribir a los amigos que me nombra y a enviarles mis últimos trabajos. (...)

Parece que "se han olvidado" de ponerme en la comisión ejecutiva del próximo Congreso Internacional de Americanistas. 
Indudablemente, mi retiro voluntario del Museo de $\mathrm{H}$. Natural ha tenido la virtud de hacer descender mis acciones entre el elemento oficial. En cambio, mi producción científica es ahora mayor que nunca y trabajo independientemente. Creo que soy el único que se ocupa de mantener el contacto con los demás colegas de América. A pesar de ello tengo ya sobre mi escritorio cuatro nombramientos de instituciones científicas que me designan como delegado al Congreso.(...)

Lamento que usted no se anime a venir, desearia conversar mucho. Si por desgracia asi fuera, le expreso que tendría un gran placer en ser delegado de su Museo, me ocuparía de leer y de defender los trabajos que ustedes me enviaran. Y si aún, no tuvieran tiempo de terminar trabajos, avisándome con tiempo yo presentaria en nombre de su Museo, o del Perú un trabajo importantísimo que tengo reservado "El concepto de la proporción en la arquitectura de los Incas", basado en el relevamiento que hice en Cuzco, en 1924, sobre el muro del Palacio del Inca Manco Capac en Colcampata. Pienso hacer honor a su ofrecimiento de colaborar en la Revista y enviárselo más tarde, si no lo termino en esta ocasión.

Quedo siempre a sus gratas órdenes. Reciba el alto aprecio de su colega y amigo

Héctor Greslebin

\subsubsection{2 ( De Valcárcel a Greslebin)}

Muy apreciado amigo:

Con mucho placer leí su carta tan amable y me apresuro en ponerle estas líneas para suplicar a Ud. represente al Museo en el Congreso. Le envío adjunta la credencial respectiva. Escribo también al Presidente del Comité.

Mucho le agradezco sus palabras amistosas y desde ya le comprometo para presentar su estudio sobre arquitectura cusqueña tanto en el Congreso como en nuestra Revista. Mande dibujos y fotografías que todo se publicará con esmero. Le envié el $2^{\circ}$ número que salió bastante nutrido. El $3^{\circ}$ está dedicado a Historia.

Por el próximo correo áereo le remitiré uno de mis trabajos ("Algunas raíces keswas") que espero concluir. Me venció el tiempo. No enviaré ya el otro estudio sobre "Esculturas de Pikillajta", que reservo para el número de la Revista.Con atentos saludos y lamentando mi inasistencia al congreso que me habria proporcionado el gusto de verle, soy siempre afectísimo colega.

Luis E. Valcárcel

\subsubsection{2 (De Greslebin a Valcárcel)}

Muy apreciado amigo y colega:

(...) Quédole muy agradecido por el nombramiento que me comunica y le manifiesto, con toda sinceridad, que es una de las mayores satisfacciones que tengo de mi vida de estudioso y uno de los más grandes estímulos en la hora actual para que continúe en la senda.

A pesar de haber vencido el plazo para la presentación de trabajos, me ha concedido el Dr. Levene permiso para que presente mañana un trabajo como Delegado del Museo Nacional del Perú. Acabo de terminar "La tendencia a la "simetría dinámica" en la forma aribalo de la cerámica del Cuzco". Son pocas páginas, pero una sugestión y una comprobación muy nueva e importante, a mi modo de ver, que parangona la cerámica del Cuzco con la griega malgrado la ausencia de torno de aquella. Es una aplicación de los trazados de Hambidge a la cerámica griega, que aquí puede aplicarse a la serie del Cuzco.

(...)Lamento su inasistencia al Congreso, pues me hubiera gustado hablar con usted de algunos proyectos para el futuro, cuando pase toda esta época de crisis, sobresaltos y revoluciones.

Las obras serias deben de prepararse con tiempo y esto es lo único que se puede hacer por el momento. 
Nuevamente muy agradecido por la alta distinción que acaba de conferirme, reciba el alto aprecio de su siempre amigo y afectísimo colega. S. S. S.

Héctor Greslebin

\subsubsection{2 (De Greslebin a Valcárcel)}

Muy estimado amigo y distinguido colega:

He demorado en darle noticias del Congreso de Americanistas, porque esperaba que el Secretario General me remitiera una copia oficial de los temas presentados al mismo $y$, además, la redacción de los votos aprobados en la sesión de clausura, lo que no he conseguido hasta ahora.

Presenté en nombre del Museo N. de Lima el trabajo titulado "La Tendencia a la "simetría dinámica" en la forma aríbalo de la cerámica del Cuzco", el cual será publicado en las actas del Congreso. En la sesión de clausura pronuncié en nombre del Museo de Lima las siguientes palabras cuya copia le adjunto.

En La Nación del 4 de diciembre la redacción de mi voto es como sigue: Del arquitecto Héctor Greslebin para que el gobierno del Perú constituya al Cuzco en capital arqueológica de América del Sur, cuidando de la conservación de sus monumentos. Este voto fue redactado definitivamente con una ampliación propuesta por el arquitecto Martín Noel.

Dice también: Del Museo Nacional de Lima, tres votos relacionados con un acuerdo entre instituciones y especialistas de Europa y de América para la intensificación de los estudios americanistas.

(...) Una misión del Museo Nacional de $\mathrm{H}$. Natural de B. Aires saldrá próximamente para Tiahuanaco a hacer estudios arqueológicos y etnográficos, pero, como usted comprenderá, por hallarme disgustado con el Museo, no me será posible formar parte de ella. Tal vez, más adelante, si la situación política cambia y vuelve a serme favorable he de ir a visitarlo a estudiar la arquitectura del Cuzco.

Le saluda con el afecto de siempre y le desea un feliz año nuevo, su amigo, colega y S. S. S.

Hector Greslebin

\subsubsection{4 (De Greslebin a Valcárcel)}

Muy estimado amigo y distinguido colega:

(...) He leído su interesante artículo de La Prensa del $1^{\circ}$ de enero de 1934 titulado "Cuzco, capital arqueológica de América". Le agradezco su recuerdo amable de mi nombre. No se imagina con qué gran placer leí en esa página que el 23 de marzo próximo se va a inaugurar el Instituto Arqueológico de Cuzco. A este respecto sigo con el mismo entusiasmo de 1924, cuando apoyé esa iniciativa en Lima.

(...) Le adjunto el trabajo que presenté en el Congreso de Americanistas de La Plata, en representación del Museo Nacional de Lima. Como han limitado por economía la publicación de trabajos me lo han devuelto, habiéndose quedado con uno mío de mayor extensión titulado "La antigüedad de la llamada civilización Chaco Santiagueña".

Aún no he tenido tiempo de terminarle el trabajo sobre la arquitectura de Cuzco, que tendrá el mismo carácter de éste que le remito. Como usted ve, son comprobaciones muy interesantes que mucho dicen sobre la noción de proporción de los americanos. Este pequeño trabajo ha gustado mucho en el Congreso, pues se me pidieron varias aclaraciones fuera de la sesión. Si usted lo encuentra bien puede utilizarlo en su Revista. En caso contrario le ruego me lo devuelva, pues es un capítulo de una obra de mayor aliento. mías.(...)

Le envío cinco nuevas publicaciones

Deseando que este nuevo año le sea 
Nuevamente muy agradecido por la alta distinción que acaba de conferirme, reciba el alto aprecio de su siempre amigo y afectísimo colega. S. S. S.

Héctor Greslebin

\subsubsection{2 (De Greslebin a Valcárcel)}

Muy estimado amigo y distinguido colega:

He demorado en darle noticias del Congreso de Americanistas, porque esperaba que el Secretario General me remitiera una copia oficial de los temas presentados al mismo $y$, además, la redacción de los votos aprobados en la sesión de clausura, lo que no he conseguido hasta ahora.

Presenté en nombre del Museo N. de Lima el trabajo titulado "La Tendencia a la "simetría dinámica" en la forma aríbalo de la cerámica del Cuzco", el cual será publicado en las actas del Congreso. En la sesión de clausura pronuncié en nombre del Museo de Lima las siguientes palabras cuya copia le adjunto.

En La Nación del 4 de diciembre la redacción de mi voto es como sigue: Del arquitecto Héctor Greslebin para que el gobierno del Perú constituya al Cuzco en capital arqueológica de América del Sur, cuidando de la conservación de sus monumentos. Este voto fue redactado definitivamente con una ampliación propuesta por el arquitecto Martín Noel.

Dice también: Del Museo Nacional de Lima, tres votos relacionados con un acuerdo entre instituciones y especialistas de Europa y de América para la intensificación de los estudios americanistas.

(...) Una misión del Museo Nacional de $\mathrm{H}$. Natural de B. Aires saldrá próximamente para Tiahuanaco a hacer estudios arqueológicos y etnográficos, pero, como usted comprenderá, por hallarme disgustado con el Museo, no me será posible formar parte de ella. Tal vez, más adelante, si la situación política cambia y vuelve a serme favorable he de ir a visitarlo a estudiar la arquitectura del Cuzco.

Le saluda con el afecto de siempre y le desea un feliz año nuevo, su amigo, colega y S. S. S.

Hector Greslebin

\subsubsection{4 (De Greslebin a Valcárcel)}

Muy estimado amigo y distinguido colega:

(...) He leído su interesante artículo de $\mathrm{La}$ Prensa del $1^{\circ}$ de enero de 1934 titulado "Cuzco, capital arqueológica de América". Le agradezco su recuerdo amable de mi nombre. No se imagina con qué gran placer leí en esa página que el 23 de marzo próximo se va a inaugurar el Instituto Arqueológico de Cuzco. A este respecto sigo con el mismo entusiasmo de 1924, cuando apoyé esa iniciativa en Lima.

(...) Le adjunto el trabajo que presenté en el Congreso de Americanistas de La Plata, en representación del Museo Nacional de Lima. Como han limitado por economía la publicación de trabajos me lo han devuelto, habiéndose quedado con uno mío de mayor extensión titulado "La antigüedad de la llamada civilización Chaco Santiagueña".

Aún no he tenido tiempo de terminarle el trabajo sobre la arquitectura de Cuzco, que tendrá el mismo carácter de éste que le remito. Como usted ve, son comprobaciones muy interesantes que mucho dicen sobre la noción de proporción de los americanos. Este pequeño trabajo ha gustado mucho en el Congreso, pues se me pidieron varias aclaraciones fuera de la sesión. Si usted lo encuentra bien puede utilizarlo en su Revista. En caso contrario le ruego me lo devuelva, pues es un capítulo de una obra de mayor aliento.

mías.(...)

Le envío cinco nuevas publicaciones

Deseando que este nuevo año le sea 
propicio en sus hallazgos y estudios reciba usted el aprecio de su siempre amigo y S.S.S.

\section{Héctor Greslebin}

\subsubsection{4 (De Greslebin a Valcárcel)}

Mi querido amigo y distinguido colega:

Acabo de recibir su atenta carta de Cuzco, de fecha 2 del corriente, en la que me incluye unas líneas para el Dr. Ricardo Rojas, cuya entrega me ha sido grato cumplir. (...)

Por sus artículos en La Prensa y por el último artículo de La Nación del 29 de éste, del amigo Harth-Terré, me doy cuenta de la importancia de la labor emprendida por ustedes. Acabo de recibir, también el tomo III p. 1-2 de la Revista de su digna dirección y en su primer artículo, debido a su pluma, he podido apreciar con más precisión aún la importancia de las nuevas excavaciones. Le felicito sinceramente por la labor emprendida, creo que por el momento es la única que puede llevarnos a resultados positivos en el terreno arqueológico. Próximamente, en octubre voy a dar una conferencia sobre Perú, para la Asociación Peruana de ésta. Voy a ocuparme del tema "Cuzco, capital arqueológica de América y el significado simbólico de su redescubrimiento". Tendré ocasión de referirme a estas nuevas tareas suyas.

Le agradezco vivamente el haber dado cabida a mi modesto artículo sobre la llamada "simetria dinámica" en los vasos aríbalos de Cuzco. Es para mí un nuevo estímulo científico y una nueva prueba de su gentileza para conmigo.

Con el alto aprecio de siempre le saluda muy afectuosamente su amigo y colega $y$ S. S. S.

Hector Greslebin

\subsubsection{4 (De Greslebin a Valcárcel)}

Mi estimado amigo y distinguido colega:
Tengo el agrado de dirigirle estas líneas para adjuntarle el resumen de mi conferencia sobre Cuzco y su redescubrimiento, dada en la Asociación Peruana el 10 del corriente y que ha sido publicada en La Nación. El señor embajador del Perú, Dr. Felipe Barreda y Laos, ha hecho gestiones para que el Perú me considere invitado oficial a las próximas fiestas del Centenario de Lima y me ha comunicado que ha sido resuelto el punto favorablemente, habiéndoseme acordado los pasajes de ida y vuelta entre Lima y Huaqui.

No tengo nota oficial sobre este viaje, pero me estoy preparando para hacerlo y para dar algunas conferencias en ésa, relacionadas con asuntos arqueológicos de Perú y de nuestro noroeste argentino.

En espera de sus noticias le saluda con la alta estima de siempre su affmo. amigo y S. S. S.

Héctor Greslebin

\subsubsection{4 (De Valcárcel a Greslebin)}

Mi apreciado amigo y colega:

Contesto su carta del 13 de noviembre que he recibido a mi regreso del Cuzco. Magnífica su conferencia de que da noticia el recorte de "La Nación" que tiene la bondad de enviarme. Está Ud. en lo justo y de completo acuerdo conmigo. Las restricciones de que Ud. habla para impedir la salida de material científico son fundamentales. El Perú ha sufrido una descapitalización arqueológica enorme. Mas, el sistema aceptado en Méjico y Centroamérica es el aconsejable ${ }^{14}$. Gracias a él han podido verificarse labores importantísimas que no costearían jamás exclusivamente nuestros gobiernos. Solo gastando decenas de millones conseguiremos acercarnos al ideal. El cateo y el trabajo de hormiga si tienen relativo interés para la ciencia, sacrifican en cambio la posibilidad de conservar y restaurar los grandes centros poblados en los

\footnotetext{
${ }^{14}$ Véase Valcárcel, Luis E., Memorias (ed. J.Matos Mar, J. Deustua, y J.L. Rénique) Instituto de Estudios Penanos. Lima. 1981, p. 286.
} 
tiempos antiguos, descubrir lo que está oculto y estudiarlo bajo todos sus aspectos, en forma definitiva.

Como hace breves días que he vuelto todavía nada sé sobre las invitaciones para el IV Centenario. Cuánto placer tendría de verlo otra vez por acá, y muy grande mi satisfacción si pudiera Ud. ir al Cuzco, donde he dejado establecido el Instituto Arqueológico.(...)

Cuando le sea posible recuérdele al maestro Ricardo Rojas el envío de su Silabario del Arte que me anunció enviar, pero que nunca recibí. Con afectuosos saludos, soy su colega y amigo

Luis E. Valcárcel

12.3.1935 (De Greslebin a Gualterio Looser de Santiago de Chile)

Mi querido amigo Looser:

(...) Me he ocupado en forma muy especial del Instituto Internacional de Arqueología del Cusco. Ya está formado. Ha quedado Valcárcel en hacer su reglamento y el gobierno en dictarlo para que, según mi iniciativa, en los diversos países americanos podamos establecer filiales que contribuyan al sostenimiento y unifiquen los estudios.(...)

Mayo de 1935. (De Valcárcel a Greslebin)

Señor:

Muy señor nuestro:

Conocedores de su versación científica y de su interés por los problemas del Perú precolombino, invitamos a Ud. a colaborar con la Conferencia Arqueológica que debe reunirse en la ciudad de Trujillo el 28 de julio próximo, en la dilucidación de los importantes asuntos enumerados en el programa adjunto.
Anticipándole nuestro agradecimiento por su participación eficaz, somos de Ud. muy atentamente.

Por la Comisión Organizadora de la Conferencia Arqueológica de Trujillo.

Luis E. Valcárcel

Nota: Los trabajos deben enviarse a la Dirección del Museo Nacional - Lima, Perú- Av. Alfonso Ugarte 650.

\section{Programa para la conferencia arqueológica de Trujillo}

A. Asuntos especiales.

1) Estudios sobre arquitectura, cerámica, metalistería, tejidos, etc. de los valles de la Costa norte del Perú.

2) Determinación de semejanzas y diferencias entre los estilos Mochika y Chimú.

3) Influencias mochikas y chimús sobre otras zonas geográficas.

4) Influencias recibidas de fuera por Mochikas y Chimús.

5) Identificación cultural de las Wakas del Sol y de la Luna y del pueblo de Chan Chan.

6) La lengua mochika.

7) Presencia en las cerámicas Chimú y Mochika de motivos exóticos o pertenecientes a otros círculos culturales peruanos.

8) Fijación del Círculo Cultural Mochika-Chimú y su denominación definitiva.

\section{B. Asuntos generales.}

1) Bases para una organización de la defensa de los monumentos históricos del Perú. 
2) Bases para establecer vinculaciones con institutos científicos extranjeros.

3) Otras cuestiones conexas.

Lima, mayo de 1935

\author{
15.6.1935 (De Greslebin al Doctor Carlos \\ Bambarén de Lima)
}

Mi inolvidable amigo:

(...)Aún no he dado conferencias sobre este nuevo viaje, pues recién me estoy ordenando. He hablado por radio tres veces y sé que ha despertado interés el asunto. El Cónsul del Perú en Buenos Aires, señor García Vegas, ha salido ya para ésa con la señora y le he encargado de ocuparse del nombramiento mío de organizador de la Filial Argentina del Instituto Internacional de Arqueología del Cuzco. (...)

Héctor Greslebin

\subsubsection{5 (De Greslebin a Valcárcel)}

Mi querido amigo y colega:

He recibido en su oportunidad su carta del 3 de abril y luego su comunicación sobre la Conferencia Arqueológica de Trujillo, que mucho agradezco. (...)

Me enteré del cambio de gabinete. Me enteré también por su carta que los proyectos sobre dotación y organización del Instituto Arqueológico de Cusco están en el mismo estado. Inspirado en su ejemplo y porque haremos siempre todo lo posible por ese Instituto, le diré que no he perdido estos últimos días.

En efecto, he tenido en ocasiones la oportunidad de conversar ampliamente con el ministro Concha. En la segunda reunión me pidió que le presentase un memorial de todo lo relatado y de mis sugerencias. Así lo hice, y me es grato adjuntarle "en carácter reservado" hasta que usted lo crea conveniente, la copia de ese memorial. Creo en él haber interpretado sus deseos y las verdaderas necesidades del Instituto. Ayer vi por tercera vez al ministro Concha en una fiesta de la "Asociación peruana" y me dijo que ese memorial "iba a ser considerado en Lima". Se que está muy bien impresionado por la visita que ha hecho al Museo de La Plata. Esto puede influir para que él defienda la necesidad de ampliar el Museo de Lima.

Además, he encargado a García Vegas, Cónsul General del Perú en ésta, que en estos momentos se encuentra en Lima, que interponga su influencia oficial en tal sentido, habiéndomelo prometido.

En el fondo, veo siempre la idea que se tiene en Lima, de no llevar adelante los estudios arqueológicos, tal vez por temor de darle mucha importancia a lo indígena. Sin embargo, por vez primera, acabo de oír hablar sensatamente a un hombre de gobierno en la persona del ministro Concha, que se siente comprensivo de tales problemas. Ha llegado en ésta hasta demostrarlo en sus actos, pues usted sabrá que la colectividad peruana se halla actualmente muy dividida: el aristocrático "Club peruano" y la "Asociación peruana" que dirige nuestro amigo Rosales. EI ministro les ha dado una lección a los primeros, asistiendo a las fiestas de la Asociación, bailando democráticamente con los "indios" y "apristas", en el decir de los aristocráticos miembros del Club Peruano. Creo que el ministro Concha puede hacer algo por el Instituto Arqueológico del Cuzco. Por mi parte, seguiré desde ésta haciendo ruido cuando se me presente la ocasión.

Di a Rojas sus saludos. Celebro que haya visitado Trujillo y que haya pasado tan buenos momentos con Rafael Larco Hoyle, tan buen amigo y estudiante entusiasta de la arqueología. Voy a dedicar estos días a trabajar intensamente para enviarles unas notas sobre arqueología muchic a la conferencia (...)

Veo en los diarios de hoy que le han caído visitas: Lee Hewet y 20 acompañantes!

Es muy difícil poder decir si muchic, 
chimú y los incas son una misma cosa. Creo que hay que desconfiar del hecho que se presenten sus restos sincronizados en profundidad, como en Salamanca. Indudablemente que después de haber visto Salamanca y las huacas de Chimú, no se sabe por dónde empezar con repecto al establecimiento de correlaciones.

No creo que con publicaciones parciales, por mejores que sean, ni con observaciones aisladas de varios arqueólogos se pueda resolver el problema. Creo que únicamente, después de haber viajado mucho por Perú un observador capacitado y después de haber hecho sondeos parciales en cada localidad para poder valorar las colecciones que le muestran y lo publicado, recién podrá iniciar la tarea de correlación. Es cuestión, después de algunos años de viajes y buenas observaciones de encontrar la escala para apreciar la enorme tarea que han realizado otros parcialmente y que creo que no es posible encontrar esta escala de medida desde el gabinete, para medir civilizaciones separadas o apreciar simples aspectos locales.

Espero su aviso acerca de la fecha de entrega de los trabajos a la Conferencia de Trujillo. Esperando también tener pronto el placer de leer sus noticias, me es grato saludarle con el alto aprecio de siempre, quedando en ésta una vez más a sus gratas órdenes.

Su amigo y colega y S. S.

Héctor Greslebin

\section{Buenos Aires, junio 25 de 1935}

Excmo. señor Ministro de Relaciones Exteriores del Perú.

Dr. Carlos Concha

Plaza Hotel. B. Aires

De mi más alta consideración:

Recordando la amable atención que me dispensó el 23 del cte. en la reunión celebrada en su honor por la colectividad peruana, ocasión en la que se dignó usted escuchar mi relación acerca de la conveniencia de asegurar el cumplimiento de las finalidades del Instituto Arqueológico del Cusco, vengo respetuosamente, de acuerdo a su pedido, a relacionar a usted los antecedentes y considerandos que en el sentir de los estudiosos del pasado americano, justifican el pedido formulado.

Ha sido siempre un anhelo de los especialistas y estudiosos del pasado remoto de la América del Sur, vincularse entre sí por un organismo panamericano que oriente una labor de conjunto y provea de una manera regular, con el concurso de los gobiernos de América, la forma de asegurar la continuidad de esta labor. En la reunión de clausura de la Subsección de Arqueología del III Congreso Científico Panamericano celebrado en Lima en 1924, a la que tuve el alto honor de asistir en mi carácter de delegado argentino, se convino lo siguiente:

"El Congreso solicitará del gobierno del Perú, que invite a los gobiernos representados en este Congreso (Argentina, Bolivia, Colombia, Ecuador y Perú) y a los que en el futuro se adhieran a nombrar sendos delegados a fin de constituir una conferencia arqueológica que se reunirá en la ciudad de Cusco, y establecería las bases para la organización y funcionamiento de un comité arqueológico permanente, encargado de realizar exploraciones sistemáticas y metódicas tendientes a esclarecer los problemas de su pasado común y a planear las bases de una Escuela Internacional de Arqueología Sudamericana que tendría su sede en el Cusco"15. Se concretó, pues, en aquella ocasión, un vivo deseo de colaboración, a fin, también de que fuera posible recoger a tiempo el enorme acervo de restos arqueolgóicos que posee la América del Sur.

En el XXVo Congreso Inrternacional de Americanistas celebrado en 1932 en La Plata (Argentina) tuve el gran honor de ser representante oficial del Museo Nacional de Lima y de la Sociedad de Arqueología del Perú. En aquella ocasión formulé la siguiente moción:

\footnotetext{
15Segrin El Comercio de Lima, del 7 de enero de 1925, se trataba de una moción firmada por los seffores D. Aparicio, Tello, Cabral, Zamudio, Muñoz, Urteaga, Mena, Gangotena, Greslebin, Saville, Gamarra Hernández y Valcárcel.
} 
"El XXVo congreso Internacional de Americanistas vería con agrado que el gobierno de la República del Perú no omitiera esfuerzos para asegurar el cuidado, el carácter y la restauración de los monumentos que tienen interés artístico y arqueológico de la ciudad del Cusco, con los ambientes necesarios, así como también planee una obra fundamental en la cual queden figurados los relevamientos y las características de los mismos". Este voto fue ampliado por mi colega argentino el arquitecto Carlos Noel en el sentido de que Cusco fuese declarada "Capital arqueológica de Sud América", lo que fue aprobado por unanimidad.

Más tarde, el Congreso Constituyente del Perú, en conocimiento de esta declaración del Congreso I. de Americanistas de La Plata, a moción del señor representante Cossio aprueba por unanimidad esta resolución, declarando a Cusco sede del Museo Nacional, creando la facultad de Historia y Arqueología Americana y Ciencias afines y estableciendo una Escuela de arte peruano, como también una oficina de difusión arqueológica y organización del turismo.

Es del caso, señor Ministro, que aquellas resoluciones del Congreso Panamericano de Lima de 1924, del Congreso Internacional de Americanistas de 1932, (...un renglón que no se lee) todas por un mismo espíritu, redactadas con las mismas palabras, como ya dijera el señor representante Cossio "no deben quedar simplemente como un voto moral de un certamen científico".

El actual Instituto Arqueológico de Cusco es un escuela de altos estudios de Arte y de

\footnotetext{
$16 \mathrm{Al}$ respecto. Valcárcel comenta en sus Memorias:"Desde hacfa varios años consideraba como cuestión ugente y de excepcional importancia científica la fundación en el Cusco de una institución semejante. Lo habŕa manifestado así en 1924, cuando fue solicitada mi opinión por la Comisión Arqueológica de la Unión Panamericana. Tiempo después, en el Congreso Científico Panamericano, celebrado en Lima, insisu en el tema. Con otros delegados logramos que en una sesión plenaria se aprobara por aclamación la decisión de fundar una Escuela Internacional de Arqueología en el Cusco. Sin embargo todo quedó allí, ante la total falta de interés del gobierno de Legufa que no quiso apoyar tan importante proyecto. Solamente algunos años más tarde pudimos llevarlo a cabo. El decreto que se emitió con motivo de las fiestas del IV Centenario de la fundación española del Cusco, tomó en cuenta la necesidad de constituir un Instituto de Arqueología y destino la partida necesaria para adquirir un local y equiparlo convenientemente." (Valcárcel, Luis E., op.cit., pp. 293-294).
}

Arqueología Indoperuanos. Es, ni más ni menos, aquella Escuela Internacional que anhelábamos en 192416. Todos los países iberoamericanos han de contribuir a dar esplendor a esta Escuela y han de remitir recursos y estudiosos para su sostenimiento material y moral. Por una comunicación que hemos recibido los especialistas, estamos informados de que el 30 de agosto de 1934 se inauguró el Instituto Arqueológico del Cusco. Mas, durante mi última estada en Lima, realizada en enero de este año, como invitado oficial de la Municipalidad de Lima a los festejos del IVo Centenario de su fundación, tuve ocasión de apreciar las verdaderas dificultades por que atraviesa el funcionamiento regular del Instituto Internacional de Arqueología del Cusco.

Con el entonces señor ministro de Instrucción, Dr. Carlos Arenas Loaizaga habíamos tenido la oportunidad de cambiar ideas y de concretar las medidas que podían convertir este centro de estudios en factor poderoso de colaboración y de armonía internacional, atendiendo, además, a la circunstancia de que todos estos materiales arqueológicos están expuestos a perderse totalmente para el estudio en un plazo más o menos breve.

Es muy necesario, a nuestro modo de ver, que el Instituto de A. del Cusco pase a ser una dependencia del Ministerio de Instrucción y que, también, dentro de este Ministerio conserve una completa autonomía. Así lo exigiría, no solo la índole de sus actividades, sino también la buena forma de administrar directamente los recursos recaudados de los países adheridos, para poder realizar con oportunidad y con éxito las labores de terreno y de publicación. Además, debe el Gobierno del Perú asegurar un subsidio en el Presupuesto para atender los gastos de dirección, empleados, conservación de local y colecciones. Aun, para mí, lo consideraría hasta desvinculado de los restantes museos del Perú, para poder trazarse un rumbo americano. Los demás institutos tienen sobrada labor con recoger y estudiar los materiales de las diversas regiones. 
En este último viaje al Perú he tenido ocasión de completar mis estudios sobre Perú visitando, en compañía del estudioso peruano Rafael Larco Hoyle el norte del Perú. Yo no encuentro exageradas las palabras del Dr. Valcárcel al decir que en cinco años más puede perderse el material arqueológico del Perú, frente a los constantes avances del progreso y a los crecientes saqueos de los huaqueros clandestinos.

Aún queda algo por decir. No bastaria asegurar el buen funcionamiento del Instituto Arqueológico del Cusco, es menester también asegurar la formación de los futuros especialistas en el número y en la calidad que los necesitan Perú y América del Sur. En este viaje me he dado cuenta de la ausencia de jóvenes estudiosos, tanto en Chile como en Perú, como en Argentina mismo. No se perfilan nuevos estudiosos que puedan asegurarnos la continuidad de estos estudios.

Este es, Exmo. señor Ministro mi pedido, de que el Honorable Gobierno del Perú preste todo su apoyo efectivo para asegurar el funcionamiento regular del Instituto de Arqueología del Cusco, lo que ha de redundar con seguridad, en una mayor armonía espiritual entre los estudiosos de América y una mejor comprensión de los factores que constituyen y definen el remoto pasado de nuestro querido país hermano, para quien los argentinos que hemos tenido el placer de conocerle solo tenemos palabras de admiración y eternos recuerdos de gratitud.

Saluda al señor Ministro con su consideración más distinguida.

Héctor Greslebin

\subsubsection{5 (De Valcárcel a Greslebin)}

Querido amigo y colega:

Recibí con placer su carta del 2 que contesto. Inmediatamente por aéreo le puse tarjeta comunicándole que el congreso de Trujillo había sido postergado hasta diciembre. Tiene Ud. pues, tiempo de escribir... ¿y de venir? Ojalá. EL INSTITUTO ARQUEOLÓGICO DEL CUZCO ESTA SALVADO, gracias a la tenacidad, a los buenos oficios de Ud. y a un conjunto de circunstancias felices de último momento. El Instituto mientras pueda crecer y emanciparse estará dentro de la organización del Museo Nacional. Su dotación económica es de mil soles mensuales, aparte de quinientos también mensuales para conservar las ruinas. Considero un magnífico éxito. Ahora nos corresponde trabajar por su internacionalización.

No he podido ver a Concha. Con Vegas García estuve la otra tarde breves momentos y alcanzó a darme sus amistosos recuerdos. Trataré de entrevistar a Concha para que ayude en lo de la Inter... Ya está prestando servicios el Instituto: trabajaron quince días en su local los del grupo encabezado por Hewett, he recomendado antes y después a un número de antropólogos, historiadores, etc. que vienen siempre de E.U. Benett, del Museo de Hist. Nat. de N. York, vendrá a trabajar seis meses: primero, en Trujilio. Recibí una carta que demuestra mucho entusiasmo.

Este año también trabajaremos nosotros con alguna intensidad. En Ayacucho y Wari, en Ancón y alrededores de Lima. Tello viajará de Cuzco a Ayacucho por toda la sierra. En primeros de agosto saldrá la Revista con 200 págs. Hay artículos de interés. Lanzamos la idea de un homenaje a Max Uhle con motivo de su $80^{\circ}$ aniversario. Publicamos su biobibliografía completísima.

En espera de sus gratas noticias, le envía un cordial apretón de manos su amigo

Luis E. Valcárcel

Recuerdos a Perlotti

20.10.1935 (De Greslebin a Valcárcel)

Mi querido amigo y colega:

Tengo el agrado de acusar recibo del 
nuevo número de la Revista del Museo Nacional, correspondiente al primer semestre de 1935. Veo, complacido, que no pierde usted el ánimo y que sigue realizando su magnífico esfuerzo, como lo demuestra este nuevo número de su Revista con tan importantes trabajos. La idea del homenaje a Max Uhle es magnífica y ya he dado noticia de ella, basado en su anterior del 18 de julio, según podrá verlo en la conferencia que di el 6 de setiembre en La Prensa, cuya copia le envío.

Cumpliendo con el deseo del Consejo Provincial de Lima y también de nuestro común amigo Vegas García, de quien acabo de recibir una amable tarjeta, está casi organizado el comité de intelectuales argentinos que va a prestigiar la Sección Argentina de la Biblioteca del Concejo Provincial de Lima. Creo que, además, voy a ser apoyado por la Embajada del Perú. Sus miembros son: Dr. Bernardo A. Houssay, Dr. Nicolas Lozano, Dr. C. Patiño Meyer, Dr. Alejandro Ceballos, Dr. Reinaldo Vanossi, Dr. Jorge Caride Masini, Sr. Staub, Sr. Miguel Solá y Dr. Ricardo Caillet Bois. Dentro de pocos días hemos de tener la primera reunión de constitución del Comité.

Pronto voy a escribir el artículo para La Prensa sobre el Museo Nacional de Lima. (...) Mucha impresión también nos ha causado el fallecimiento de nuestra amiga, la eminente escritora Angélica Palma. Por suerte la hermana sigue mejor. ¿Habrá un lugarcito para mí en el tomo de Uhle? ¿Cómo siguen los trabajos del Congreso de Arqueología de Trujillo?

Sin más, esperando sus siempre gratas noticias, reciba ud. un fuerte apretón de manos de su afmo. amigo y colega.

Héctor Greslebin

Muchos recuerdos a Vegas García, Tello, Dr. Herrera, y demás amigos.

28.3.1936 (De Luis Pardo, Jefe del Instituto Arqueológico del Cusco, a Greslebin)

EL SEMINARIO DE ALTOS ESTUDIOS DEL
INSTITUTO ARQUEOLOGICO DEL CUSCO, en sesión del día 14 de enero del presente año y previa aprobación de sus respectivos estatutos, ha tenido a bien nombrar a Ud. como SOCIO CORRESPONSAL de esta Institución.

No dudamos que su espíritu cusqueñista ¡su gran amor por los estudios históricos y arqueológicos sabrán honrar nuestro Seminario con su colaboración ! sus importantes estudios e investigaciones.

Dios guarde a Ud.

Julian Santisteban Ochoa Luis A. Pardo

Secretario Jefe del Instituto Arqueológico del Cusco

28.3.1936 (De Luis Pardo, Jefe del Instituto Arqueológico del Cusco, a Greslebin)

EL SEMINARIO DE ALTOS ESTUDIOS DEL INSTITUTO ARQUEOLOGICO DEL CUSCO, en asamblea de 14 de enero del presente año, ha acordado comunicar a Ud., los siguientes puntos fundamentales para el mejor cumplimiento de sus labores:

- Que tiene por plan primario, las cuatro secciones, que al crearse el Instituto Arqueológico, se dividieron el campo en sus investigaciones: a) Histórica, b) Arqueológica, c) Antropológica y d) Artística.

- Que dentro de ese plan general, el Seminario de especialización presentará su programa de trabajo en general i el posible para su realización dentro del presente año.

- Que finalmente este plan especial i los trabajos individuales se envíen al Director del S.D.A.E. para que en vista de ellos, se pueda proceder al trabajo i la publicación de una revista, i que por lo tanto lleguen a entregarse antes del primero de mayo próximo.

- Además, como resultado de los 
acuerdos transcritos más arriba, cada uno de los seminarios pueden entrar ya en su periodo de actividad, para lo cual el Instituto Arqueológico pone a disposición su local i las facilidades del caso.

Así mismo pongo en conocimiento de Ud. que en la indicada asamblea se reconoció como Director nato del S.D.A.E al Jefe del Instituto Arqueológico, que fueron elegidos Fiscal Secretario, los señores J. M. Franco Inojosa Julian Santisteban Ochoa, respectivamente.

Me permito con esta oportunidad hacer el llamado a su amor por el pasado americano, a las ciencias que aportan a su mayor conocimiento, para que siga Ud. en su afán perseverante de estudios que S.D.A.E responda a su creación.

\section{Atentamente}

Luis A. Pardo

\subsubsection{6 (De Greslebin a Luis Pardo de} Cuzco)

De mi alta consideración:

Tengo el agrado de acusar recibo de sus dos atentas notas de fecha 28 de marzo del corriente, recién llegadas a mis manos, mediante la atención del señor L. Cárdenas Gazcón, en las que me comunica mi designación de CORRESPONSAL del Instituto de su digna dirección y su plan primario de trabajo y constitución.

Vengo a agradecer al señor Director tan honrosa designación, que acepto muy complacido, expresándole que he de poner mi mayor empeño para colaborar de una manera efectiva en el logro de los altos fines que persigue la institución.

Por este mismo correo envío a usted una colección de mis publicaciones sobre Arqueología Americana destinada a la Biblioteca del Instituto.
Rogando a usted quiera nuevamente aceptar mi agradecimento y ser intérprete de mis sentimientos ante sus dignos camaradas por esta gentil designación, le saluda con su consideración más distinguida.

Héctor Greslebin

\subsubsection{6 (De Luis Pardo a Grelebin)}

Por la presente tengo el agrado de acusar recibo de su estimable comunicación última, por la que se sirve Ud. enviarme sus valiosos e importantes trabajos que los voy leyendo actualmente. Muchas gracias.

Quiero aprovechar de esta comunicación para invitarle muy cordialmente a que colabore en la Revista del Instituto Arqueológico de esta capital y cuyo primer número le será enviado presto.

Con las seguridades de mi alta consideración personal, reciba Ud. el testimonio de mi deferencia.

Dios guarde a Ud.

Luis A. Pardo

Jefe del Instituto Arqueológico del Cuzco

\subsubsection{6 (De Luis Pardo a Greslebin)}

Por la presente nota, agradezco a Ud., por el envío de sus valiosos estudios que los voy leyendo actualmente con sumo interés, a la vez que le presento mis disculpas por no haberle acusado recibo con la oportunidad debida a causa de haber estado ausente en Machu Picchu con motivo de unas exploraciones.

Dios guarde a Ud.

Luis A. Pardo

Jefe del Instituto Arqueológico del Cuzco 


\subsubsection{6 (De Valcárcel a Greslebin)}

Querido amigo Greslebin:

Acabo de regresar de los Estados Unidos, donde he pasado cerca de cuatro meses, primero curándome en la Clínica Mayo y después recorriendo las principales ciudades de aquel gran país. Tuve oportunidad de visitar 24 museos, en muchos de los cuales admiré organización y colecciones.

Hace tiempo que no tengo noticias de Ud. ¿Qué ha publicado? Supongo que le llega puntualmente nuestra revista: está por salir el II vol. de este año. Mándeme algo para el próximo número. Del Congreso de Americanistas nada puedo decirle porque la comisión organizadora presidida por Riva Agüero, no funciona.

El portador de estas líneas es Alejandro González, un muchacho de positiva valía como artista del nuevo Arte de América. Se lo presento y le ruego hacerlo con sus amigos, recomendándolo con toda eficacia. Conversará con Ud. sobre sus interesantes proyectos. Ojalá que Buenos Aires lo acoja como sabe hacerlo a los intérpretes de la América Nueva.

Con un fuerte apretón de manos, soy muy suyo

Luis E. Valcárcel

\subsubsection{6 (De Greslebin a Valcárcel)}

Mi querido amigo Valcárcel:

Recibí su atenta carta del 26 de octubre del corriente, de la cual era portador el joven Alejandro González, a quien tuve el placer de conocer y la satisfacción de darle una recomendación, cuyo resultado ignoro, pues desde hace algún tiempo no le he vuelto a ver.

Veo por su carta que ha estado enfermo y espero que al presente se encuentre ya completamente restablecido. Indudablemente que debe haber sido una gran enseñanza el haber visitado esos 24 museos de Norteamérica.
Siempre estoy pensando en ir a conocer aquelio, que me interesa desde un doble punto de vista, como arquitecto y como arqueólogo. Tal vez la ocasión sea la del próximo Congreso Internacional de Americanistas, pero usted me da muy malas noticias en su carta respecto a las actividades de la comisión ejecutiva del Congreso. El embajador Barreda me ha prometido en esta ocasión el viaje hasta Lima y haciendo un pequeño esfuerzo de mi parte he de llegar a México.

El domingo pasado estuve con Concha, en una comida de la Asociación Peruana. Fue la oportunidad para que le agradeciera personalmente cuanto había ya hecho por el Instituto de Cuzco. Me reiteró su amistad y su deseo de atender mis pedidos. Su revista la recibo puntualmente y le felicito por su esfuerzo. También he recibido unos cuadernos de arte, muy interesantes.

A propósito de esto, ¿leyó usted mi artículo de "La Crónica" de ésa, aparecido el 13 de setiembre de 1936, pp. 13 y 22 , que me fue solicitado por Larco Herrera?

No debe de extrañarle mi silencio. He vuelto a instalar mi estudio de arquitecto en el centro, convencido que no tengo por el momento otra manera de hacer arqueología. Continúo siempre en mi cátedra del Instituto $\mathrm{N}$. del Profesorado y, además, este año me han nombrado profesor de dibujo lineal en la Escuela Industrial de la Nación Oeste, con 4 horas semanales. En fin, puede ser que de aquí en otros 20 años me completen la cátedra!

En mi estudio he formado un pequeño seminario privado de arqueología americana, el que es visitado regularmente por ex alumnos míos del profesorado y donde también hemos comenzado algunos estudios monográficos. Creo que es lo único positivo que puedo hacer por la arqueología americana, es decir, despertar vocaciones, tarea que no han hecho aún los colegas.(...) Le agradezco su invitación para colaborar en la Revista. He de hacerlo pronto.

Reciba un fuerte apretón de manos y mis 
mejores votos de felicidad para el nuevo año.

Suyo affmo.

\subsubsection{7 (De Greslebin a Valcárcel)}

Mi querido amigo y distinguido colega:

Estas pocas líneas son para adjuntarle con mis mejores saludos la hoja dedicada de La Prensa del 4 de abril pasado, en la cual me ocupé del Museo Nacional de Lima.(...)

$\mathrm{He}$ recibido su interesante trabajo Mirador Indio, que mucho le agradezco. También he leído en La Prensa, con el mayor interés, el hallazgo del ídolo de oro de Lambayeque, pareciéndome esa comprobación sumamente importante. Por aquí seguimos siempre con nuestro entusiasmo, contando únicamente con nuestras propias fuerzas. (...)

Reciba usted las seguridades de mi mejor afecto y el alto aprecio de siempre de su amigo y colega.

Héctor Greslebin

\subsubsection{7 (De Valcárcel a Greslebin)}

Querido amigo y colega:

Acabo de regresar de Europa después de una residencia de cerca de ocho meses en París y una gira por Alemania, Italia, Suiza, Checoslovaquia, Bélgica e Inglaterra. Visité más de cien museos y galerías de arte, exposiciones y la gran Exposición de 1937, maravilloso alarde de técnica y arte moderno. Tuve la suerte de organizar el Pabellón Peruano en la mencionada Exposición, con muy halagadores resultados, pues fue muy aplaudido por la prensa francesa. EI motivo autóctono siempre triunfante.

Encuentro su amable carta y el magnífico artículo que publicó Ud. en "La Prensa" en que ha sintetizado admirablemente los fines que persigue nuestro Instituto. Mil gracias. Me complace la noticia que me transmite Ud. sobre sus actividades. Es indeclinable y gallarda su fe. Muy digna de ser coronada por los mayores éxitos.

Nada puedo decirle todavía sobre el Congreso I. de Americanistas. En estos días conversaré con el Ministro de Relaciones Exteriores y con el Dr. José de la Riva Agüero, Presidente de la Comisión Organizadora.

Lo saludo afectuosamente y le deseo muchas felicidades en el año próximo.

Su colega y amigo

Luis E. Valcárcel

\subsubsection{8 (De Greslebin a Valcárcel)}

De mi consideración:

Llegue a usted, por intermedio de mi distinguido amigo el Dr. Enrique Loudet, Secretario de la Delegación Argentina a la VIII Conferencia Internacional Americana, mi afectuoso saludo y el más sincero testimonio de respeto y grato recuerdo.

Formulo mis fervientes votos para que de las deliberaciones de esta VIII Conferencia Internacional Americana, surjan resoluciones que faciliten la tarea de devolver a las generaciones presentes y futuras los muchos títulos que posee América para dictarse su propia cultura y practicar los sentimientos que más se identifican con su idiosincrasia.

Acepte usted, mi distinguido amigo, el alto afecto de siempre, que le profesa su afmo. y S. S. S.

Héctor Greslebin

\subsubsection{3 (De Luis Pardo a Greslebin)}

Mi distinguido señor y amigo:

Tengo la grata complacencia de saludar a Ud. muy atentamente, haciendo votos por su cumplida salud. 
Conocedor de los altos prestigios en el campo de la investigación del pasado de América $y$ de su enorme bagaje cultural en estudios históricos, me permito indicarle lo siguiente, pidiéndole, desde luego, disculpas por la forma como lo hago.

Se trata de establecer en esta Universidad Nacional del Cuzco, al año entrante una Sección de Arqueología, para lo que se necesita un Profesor de los prestigios de Ud. Ojalá pudiera aceptar el venir a ésta, a fundar dicha Sección. El haber que se le otorgaría es de $\mathrm{S} / 1000$ mensuales, facilitándosele pasajes de ida y vuelta desde la Argentina al Cuzco y viceversa. El término sería por uno o dos años, conforme Ud. indicara.

Le agradeceré se sirva indicarme a la brevedad posible si acepta o no i en este último caso, le ruego se moleste ponerme en relación con algún otro estudioso que quisiera aceptar este cargo.

Aprovecho de la presente oportunidad, para expresarle los sentimientos de mi alta estima personal.

Muy atentamente y S.S.

Luis A. Pardo

Director del Instituto y Museo Arqueológico de la Universidad del Cuzco, Perú.

\subsubsection{3 (De Greslebin a Luis Pardo)}

Mi apreciado amigo y muy distinguido colega:

En mi poder su amable carta del 30 de noviembre del corriente, por la cual tiene la gentileza de invitarme a establecer en la Universidad del Cuzco, la Sección de Arqueología, para el próximo año.

Aprecio altamente, en todo cuanto significa, esta importante invitación que usted me trasmite, estimando que más que a mis humildes méritos se realiza al Instituto N. del Profesorado
Secundario de B. Aires, donde dicto esta asignatura desde hace 20 años.

Mas, a pesar de cuánto me veo halagado personalmente y como americanista, debo expresarle, con verdadera pena, que por importantes motivos personales, profesionales y de familia $-y$ no por otros- no me será posible aceptar en esta ocasión tan honrosa designación. No se imagina usted cuánto siento no poder repetir mi viaje de 1924. A medida que el tiempo pasa se sedimenta en mi espíritu todo lo que tiene de grande y de verdadero este pasado americano. No desespero llegar nuevamente a Cuzco, a quien tuve el honor de bautizar como "Capital arqueológica de América del Sur" en el Congreso Internacional de Americanistas del año 1932.

Siempre estará esta cátedra del Instituto $\mathrm{N}$. del $\mathrm{P}$ de Buenos Aires que dirige el Dr. Oliverio Tracchia, deseosa de colaborar con ustedes, en la medida de sus alcances, en la noble tarea de reconstruir nuestro hermoso pasado americano, colaboración que me es grato brindar tanto a usted personalmente, como al especialista que se haga cargo de las nuevas tareas. Tareas que significan estrechar aún más, si ello es posible, los vínculos espirituales que unen a nuestros países hermanos.

Aprovecho esta oportunidad para expresarle que he recibido completa, hasta los números 10 y 11 , puntualmente, la muy interesante "Revista del Instituto Arqueológico" de su digna dirección, en la cual he tenido la satisfacción de ilustrarme, especialmente a través de sus destacadas colaboraciones, poniendo al día mi cátedra con la mención de sus nuevos esfuerzos.

Saluda a usted muy atentamente.

Héctor Greslebin

\section{Anexo}

Se incluyen acá algunos textos a modo de complemento. Se consideró oportuno reproducir los textos de Valcárcel y Greslebin 
publicados en Buenos Aires en 1934 y 1936 por su relación con los temas tratados en las cartas. El informe de Greslebin da cuenta del origen de su relación con Valcárcel.

Informe elevado por Greslebin al director del museo, profesor Doello Jurado, sobre su viaje a Chile, Perú y Bolivia de 1924-25

"En Lima tuve ocasión de conversar con el doctor Valcárcel, entregándole su carta y expresándole el deseo nuestro de que se continuaran las negociaciones iniciadas para realizar estudios en conjunto. Quedamos en reunirnos con el doctor Valcárcel, para planear el borrador de un convenio, el cual se presentaría al señor rector de la Universidad de Cuzco para su aprobación, pues esta Universidad posee en la actualidad la vigilancia e inspección de los trabajos arqueológicos que se realicen en el Departamento de Cuzco. No fue posible por inconvenientes materiales, reunirse con el doctor Valcárcel, quien estaba de acuerdo en que se debía de reservar una zona de estudio para que el Museo de Buenos Aires trabajase con la Universidad del Cuzco durante un determinado número de años.

Al llegar a Cuzco me entrevisté con el doctor Cosme Pacheco, rector de la Universidad, quien se mostró muy entusiasta para que realizáramos el plan concertado con Valcárcel en Lima. Además me dijo que el Museo sería invitado a colaborar en las excursiones que se realizarían en este próximo mes de junio o julio, y posteriormente a todas las investigaciones que hiciese la Universidad. El doctor Cosme Pacheco me mostró el Museo Arqueológico de la Universidad y hemos concertado el canje, especialmente de cerámica."

"Cuzco capital arqueológica de Sudamérica ", por Luis E. Valcárcel. La Prensa, $1^{\circ}$ de enero de 1934, Buenos Aires

En el XXV Congreso Internacional de Americanistas de La Plata, Martín S. Noel y
Héctor Greslebin obtuvieron un notable y justiciero homenaje a la ciudad de Cuzco. EI prestigioso Congreso proclamó a la ciudad incaica como capital arqueológica de Sudamérica, inigualado honor que el Perú agradece y que los cusqueños aceptan con un legítimo timbre de orgullo. Más aún, como un estímulo para hacer digna a la ciudad de tan elevado galardón.

El 23 de marzo próximo cumpliranse 400 años de la fundación española de Cuzco por Francisco Pizarro y el establecimiento de su primer cabildo. El Congreso peruano ha dado una ley para conmemorar oficialmente esa fecha histórica, y las instituciones cuzqueñas se preparan a inaugurar en tal día en el Cuzco un museo resplandeciente en sus glorias artísticas limpio de excrecencias, $\sin$ alteraciones, restaurado.

Será un acontecimiento de altísima significación americana, del cual deberán participar todos los pueblos del continente, $y$ aun los de Europa y Asia. Los gobiernos y las instituciones de cultura tendrán representación en la medida de su interés. Sería llegada la oportunidad de establecer una más estrecha vinculación intelectual y artística. Universidades y academias deben pensar desde ahora en mandar al Cuzco sus personeros, porque el 23 de marzo debe inaugurarse también, el Instituto Arqueológico, aquella escuela internacional de arqueología cuya creación fue aprobada por el $3^{\text {o }}$ Congreso Científico Panamericano de 1925, la cual, según se proyecta, será un centro de altos estudios americanistas, de Indología como se llama ya en Alemania, esta nueva ciencia del Homo Americanus. Pero este Instituto Arqueológico que deberá llamarse después, simplemente, escuela de Indología- no sólo será una academia más, un centro docente de mera transmisión de conocimientos, sino que deberá ser, sobre todo, un palenque y un laboratorio de investigaciones originales, de actividades científicas y artísticas.

En 1925 los delegados de los países que formaron parte del imperio de los Incas se comprometieron a conseguir de sus respectivos 
gobiemos apoyo efectivo, de indole también económica, para tundar y sostener la escuela del Cuzco. Ha llegado el momento de cumplir el voto del Congreso y de realizar los generosos propósitos de cooperación activa en esta empresa de hondo y verdadero americanismo.

Recuérdese la unánime acogida que tuvo el proyecto también aprobado de celebrar en el Cuzco la primera Conterencia Arqueológica Panamericana; es la oportunidad, ahora, de darse cita en la capital incaica en la techa de la conmemoración. Esa conterencia tendría por principal objeto discutir el plan de la escuela y su financiamiento. Por su parte, el Cuzco ofrecerá el edificio adecuado donde se establezca y la dotación del equipo necesario para los trabajos de exploración y los de gabinete y laboratorio. No se organizarà como las escuelas de tipo oorriente; el proposito principal es atraer al estudioso extranjero, establecer intercambio de investigadores y artistas, trabajar en consorcio los hombres de distintos paises empeñados en el común interés de resolver los problemas que plantea no sólo la prehistoria, sino la actualidad indoamericana. A diferencia de ofros pueblos, estos que formaron el Tawantinsuyu siguen viviendo del rescoldo de sus antiquísimas culturas. El fenómeno amerindio es tan complejo, precisamente porque en él se entremezclan elementos y tactores biológicos, psicológicos y sociales de distinta naturaleza. En estos paises de fuerte población indígena, viven con idéntica intensidad la tradición de las razas autóctonas, que arranca de millares de años, y la tradición española, que es de ayer, pero que también ha penetrado en el tondo espiritual de nuestros. pueblos,

$Y$ ninguna ciudad concilia como el Cuzco esta doble corriente histórica. La arquitectura española se ha superpuesto a la incaica, sin destruirla; por el contrario, ésta es el cimiento y sostén de aquélla. Plazas y calles, rincones y altozanos, palacios y templos, humildes residenclas, todo emerge de un ambiente de inexplicable misterio. De aquí la atracción para el artista y para el arqueólogo. Uno y otro quieren arrancarle el secreto que atesora, anhelan expresarlo con el lenguaje del arte o de la ciencia. Y ésta que podia ser sólo una ciudad museo, un centro de muertas reliquias, de simples recuerdos, es un foco potente de vida nueva y afirmación vigorosa, de verdadera voluntad de duración o anhelo de eternidad,

Como Roma, el Cuzco ofrece el grandioso contraste de las cosas creadas para ser eternas y de aquellas otras que son ya ruinas desde que se construyen. Bien dice Unamuno que es al contemplar las ruinas en que muerden los siglos cuando se nos antoja que los años. lejos de huir escurriéndose, quédanse y se fijan, pues nada como una ruina robusta da la sensación de permanencia.

Ruinas robustas son las de Cuzco, todas de piedra, $y$ de qué impresionantes dimensiones, como para aturdir con su magnitud, y demostrar que quienes las erigieron pensaban orgullosamente que nadie alcanzaría a superarlos.

No solo lecciones de belleza, sino de energla, de voluntad de poder, de ciencia, de dominio sobre la tierra, sobre las fuerzas naturales, se recogen en la vieja capital de los incas. Ningún ambiente mejor para una escuela de Indologia. Con una maravillosa intuición se venera al Cuzco. Adivinase acaso que de este germinal de las culturas extintas brotará la semilla de la nueva civilización de Indoamérica. Y el artista, el creador por excelencia, es el primero que viene en peregrinación a Cuzco, y es para todos como un camino de Damasco en que encuentran su definitivo rumbo.

La intelectualídad del Peró, y muy en particular la de Cuzco, anhela que con ocasión del centenario que se va a conmemorar en marzo próximo, los espiritus ansiosos de americanidad tomen la ruta que señalamos. En la capital arqueológica de Sudamérica serăn fraternalmente recibidos. 
Cuzco, capital arqueológica de la América del Sur y el significado simbólico de su redescubrimiento; por el arquitecto Héctor Greslebin, La Nación, 11 de noviembre de 1934.

"Los nuevos trabajos de restauración del Cuzco. (...) son un símbolo porque expresan para el Perú la conciencia de su capacidad científica y técnica puesta al servicio de su ideal histórico. Es decir, comienza a cumplirse la segunda etapa a que hiciéramos alusión anteriormente, la etapa de la excavación, de la restauración. Está bien la colaboración del extranjero que preconiza Valcárcel al explicar el funcionamiento del Instituto Arqueológico del Perú, "el propósito principal es atraer al estudioso extranjero, establecer el intercambio de investigadores y artistas, trabajar en consorcio los hombres de los distintos países empeñados en el común interés de resolver los problemas que plantea, no sólo la prehistoria, sino la actualidad indoamericana". Pero a mi modo de ver no debe ese consorcio extranjero prestarse sin método, superponerse con el esfuerzo nacional, llevar a su país de origen el material extraído y permitirse todavía cambiar nombres a los ríos y a los valles. Mucho me duele en este momento como hombre de ciencia y como argentino que una expedición norteamericana venida a la Patagonia se haya llevado material paleontológico típico, piezas únicas que ahora figuran en el catálogo del museo americano, a pesar de la existencia de la ley 9080 , habiendo prestado su tácita aprobación uno de los funcionarios encargados de hacer cumplir esta ley.

"Estas nuevas excavaciones de Cuzco son finalmente un símbolo, porque es con estos materiales, directamente extraídos por el arqueólogo competente que debe escribirse la nueva arqueología americana, según ha sido dicho en el Congreso Panamericano de Lima de 1924. No es posible que los museos americanos se conviertan en bazares por las continuas compras a coleccionistas y comerciantes. Esas enormes sumas que invierten los gobiernos bien pudieran emplearlas en estimular a sus investigadores y discípulos, al mismo tiempo que obtienen un material legítimo, documentado. Yo no dudo que estos esfuerzos de los investigadores y del gobierno del Perú han de continuar. Es nuestro mayor anhelo poder agregar nuestro grano de arena cuando las circunstancias económicas de orden personal o institucional así lo permitan."

"La conservación del Cuzco incaico y colonial" por Héctor Greslebin, en La Péñola, 21 de Julio de 1936, Buenos Aires.

(...)Y el voto unánime del XXV Congreso Internacional de Americanistas no ha quedado como una simple expresión de anhelos del selecto grupo de estudiosos del pasado de América. El Honorable Congreso del Perú, a moción del señor Cossio, corroboró en una declaración oficial aprobada por unanimidad, aquella declaración del Congreso Internacional de Americanistas. Los organismos cuya creación se establece, el Museo Nacional con su sede principal en Cuzco y la Facultad de Historia y Arqueología Americana y Ciencias afines, han de impulsar y centralizar, indudablemente, a estos estudios de americanística por la debida senda. Pero es de una manera especial que a los artistas americanos nos interesa la creación de la escuela de arte peruano en el Cuzco que dispone la misma resolución, para realizar la aplicación moderna del arte americano autóctono, por cuya implantación hemos bregado siempre con la palabra y con el humilde ejemplo de nuestra obra, desde hace veinte años, en medio de la más absoluta indiferencia oficial.

El voto del Congreso del Perú concreta anhelos expresados no solamente en el XXV Congreso Internacional de Americanistas, sino también aquellos anteriormente enunciados en el Tercer Congreso Científico Panamericano celebrado en Lima en 1924, al que tuve el honor de concurrir en carácter de delegado argentino.

Ya veíamos acercar la edad madura sin que se vislumbrara en el ambiente americano la forma posible de concretar una fructífera 
investigación del pasado de América del Sur, que además permitiera entregar los elementos artísticos recogidos en forma ordenada, a los artistas modernos. Con las sabias disposiciones que acaba de tomar el gobierno del Perú, podríamos decir que ya incide el sol por lo alto del blanco muro de adobe del español en la ciudad imperial, mostrándolo encaramado, desde hace cuatro siglos sobre el grisáceo cimiento de piedra de los incas. Ya le vemos ascender en el espacio y atravesar la estrecha calleja y besar las primeras hiladas de piedra de sus muros grises. $Y$ tal es nuestra esperanza y nuestra fe, que le vemos ya reflejarse en el largo y estrecho camino de piedra formado por grandes lajas lustradas por el milenario frote de la usuta. $Y$ aún, en el transcurso de estas investigaciones hemos de alcanzar a ver ese sol de los incas acariciando la descubierta hilada inicial de la augusta fábrica, para luego señalar en su diario recorrido a la consideración de los pueblos de su raza, el secreto de un antiguo poderío, la majestad de sus actos y la belleza ahora comprendida por América de sus lineas y de sus formas.

\section{Agradecimientos}

Quiero agradecer especialmente a la familia Greslebin por haberme permitido consultar la correspondencia del arquitecto Héctor Greslebin, y a su hijo Alberto por las largas charlas mantenidas sobre su padre, las cuales me orientaron en mi trabajo.

\author{
Isabel Iriarte \\ Museo Etnográfico "Juan B. Ambrosetti" \\ Universidad de Buenos Aires \\ Buenos Aires, Argentina \\ bei@step.net.ar
}

№ 1, Enero 2000 